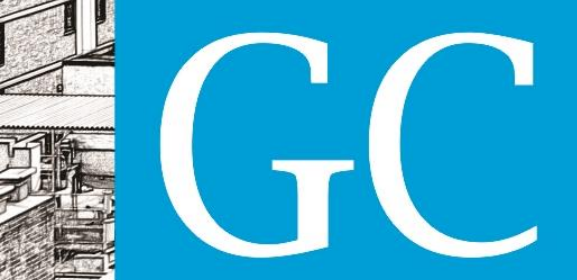

Revista Nacional de

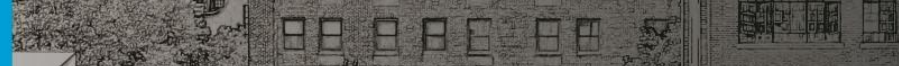

Gerenciamento de Cidades

National Joumal of Cities Management

\title{
Mensurando Qualidade de Vida Urbana: experiências internacionais
}

Measuring Urban Quality of Life: international experiences

Mensurando Calidad de Vida Urbana: experiencias internacionales

Fabio Silva Santos

Historiador, Brasil

Mestre em Relações Internacionais, Universite D'Aux-Marselle-I, França cidades.vivas@gmail.com

Douglas Gallo

Professor Mestre, IFSP, Brasil Doutorando em Urbanismo, PROURB/FAU/UFRJ, Brasil douglas.luciano@yahoo.com.br 


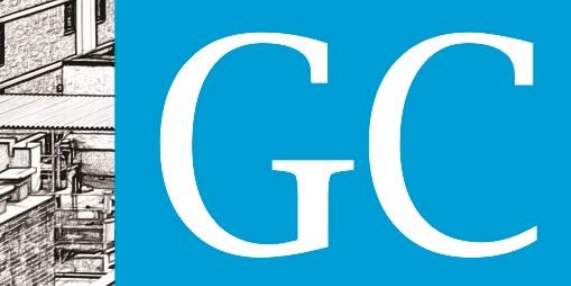

Revista Nacional de

\section{RESUMO}

O objetivo deste artigo é discutir a construção de índices de qualidade de vida urbana, bem como analisar alguns exemplos internacionais. O planejamento e gestão urbanos utiliza indicadores sociais, urbanos e ambientais para o desenho, avaliação e acompanhamento de políticas públicas. Para alcançar o objetivo foi realizada ampla revisão bibliográfica e documental, utilizou-se a análise de conteúdo para tratar do material. Foram incluídos no estudo: Norma ISO 37120 Desenvolvimento Sustentável das Comunidades - Indicadores de Serviços e Qualidade de Vida, Questionário de Qualidade de Vida da OMS (WHOQOL-100 e WHOQOL-Bref), Índice de Qualidade de Vida Urbana Comunas e cidades do Chile, Experiência "Como Vamos em Colômbia - Rede Colombiana de Cidades "Como Vamos", Índice de Qualidade de vida Urbana Colombiano e Qualidade de Vida Urbana em Porto - Portugal. A elaboração desses índices passa pela discussão de quais indicadores podem refletir o acesso e a disponibilidade de bens e serviços urbanos essenciais. Observa-se um predomínio da dimensão ambiental nas experiências internacionais, seguida das dimensões econômica, de infraestrutura e sociocultural. Embora em sua grande parte utilizem dados secundários de caráter objetivo, reforçamos a importância de se considerar os aspectos subjetivos e de percepção numa abordagem mais integral da qualidade de vida urbana.

PALAVRAS-CHAVE: Planejamento e gestão urbana. Indicadores sociais. Políticas públicas.

\section{ABSTRACT}

This study aimed to discuss the construction of Urban Quality of Life Index, as well to analyse some international reference cases. Urban planning and management uses social, urban and environmental indicators for the design, evaluation and monitoring of public policies. In order to reach the objective, a broad bibliographical and documentary review was carried out, content analysis was used to deal with the material. Included in the study were: ISO 37120 Sustainable Development of Communities - Indicators for City Services and Quality of Live, WHO Quality of Life Questionnaire (WHOQOL-100 and WHOQOL-Bref), Urban Quality of Life Chile, Experience "How are we doing - in Colombia - Colombian Network of Cities" How are we doing ", Colombian Urban Quality of Life Index and Urban Quality of Life in Porto - Portugal. The elaboration of these indices involves the discussion of which indicators may reflect the access and availability of essential urban goods and services. It is observed a predominance of the environmental dimension in the international experiences, followed by the economic, infrastructure and sociocultural dimensions. Although for the most part they use objective secondary data, we reinforce the importance of considering subjective and perceptual aspects in a more holistic approach to urban quality of life.

KEYWORDS: Urban planning and management. Social indicators. Public policies.

\section{RESUMEN}

El propósito de este ensayo es discutir la construcción de índices de calidad de vida urbana, así como analizar algunos casos referencia internacional. La planificación y gestión urbana utiliza indicadores sociales, urbanos y ambientales para el diseño, evaluación y seguimiento de políticas públicas. Para alcanzar el objetivo se realizó amplia revisión bibliográfica y documental, se utilizó el análisis de contenido para tratar el material. Para alcanzar el objetivo se realizó amplia revisión bibliográfica y documental, se utilizó el análisis de contenido para tratar el material. Se incluyeron en el estudio: Norma ISO 37120 Desarrollo Sostenible de las Comunidades - Indicadores de Servicios y Calidad de Vida, Cuestionario de Calidad de Vida de la OMS (WHOQOL-100 y WHOQOL-Bref), Índice de Calidad de Vida Urbana Comunas y ciudades de Chile, Experiencia "Como Vamos en Colombia - Red colombiana de Ciudades "Como Vamos" índice de calidad de vida urbana de Colombia y calidad de vida urbana en Porto - Portugal. La elaboración de esos índices pasa por la discusión de cuáles indicadores pueden reflejar el acceso y la disponibilidad de bienes y servicios urbanos esenciales. Se observa un predominio de la dimensión ambiental en las experiencias internacionales, seguida de las dimensiones económica, de infraestructura y sociocultural. Aunque en su gran parte utilizan datos secundarios de carácter objetivo, reforzamos la importancia de considerar los aspectos subjetivos y de percepción en un enfoque más integral de la calidad de vida urbana.

PALAVRAS CLAVE: Planificación y gestión urbana. Indicadores sociales. Políticas públicas. 


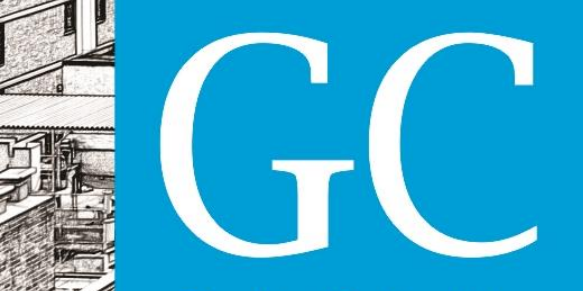

Revista Nacional de

mais equitativos a serviços e bens, promovendo a inclusão social e a equidade.

Existem duas abordagens principais na elaboração de indicadores de qualidade de vida urbana, uma objetiva e outra subjetiva. A primeira abordagem considera que as condições objetivas de vida, ou seja, os recursos aos quais os indivíduos têm acesso, tais como renda, propriedade, conhecimento, relações sociais e segurança, determinam a qualidade de vida. Estes, avaliam características do ambiente urbano, como equipamentos, serviços e redes de infraestrutura, utilizando dados secundários. Já a abordagem subjetiva considera que a qualidade de vida seja determinada pela percepção que o indivíduo tem de sua própria vida e, portanto, deveria ser aferida por indicadores subjetivos, como as medidas de satisfação e felicidade (NAHAS, 2015).

Os indicadores objetivos não consideram os laços que o sujeito tem com sua cultura e sua intepretação pessoal do vivido, enquanto os indicadores subjetivos terão dificuldade de fugir do modelo ideológico dominante e normalmente não dão conta do silencia a que são relegadas as necessidades de grupos sócias mais vulneráveis (TACCHI, 2007). Um sistema de indicadores que considere aspectos conceituais e metodológicos adequados pode ser útil para o planejamento municipal, subsidiando a formulação de políticas públicas e monitorando a qualidade de vida, especialmente em grandes cidades. Para tanto, o maior desafio que as administrações municipais enfrentam é a manutenção de sistemas de informação que possam disponibilizar indicadores fidedignos e de forma contínua, a fim de balizar e monitorar o desenvolvimento de um índice de qualidade de vida urbana (NAHAS, 2009).

Quando se diferencia entre quantidade e qualidade de vida, ambas gradações são importantes para determinar quão boa é a vida das pessoas. Indivíduos cujas vidas tem grande qualidade, seja qual medida utilizada, se tiverem uma morte prematura não terão uma vida muito boa. Nossos planos de vida são desenvolvidos, o mais tardar, na adolescência e comumente são redefinidos conforme a vida se desenvolve. Ao terminar a vida prematuramente, devido a enfermidades ou padecimentos, a pessoa não só perde as experiências, felicidade e satisfação que teria nos anos vindouros, mas também perde a oportunidade de completar projetos de longo prazo e de alcançar a vida em toda sua conformação, coerência e conclusão de seu planejamento. Assim, completar e terminar um plano de vida é o que ajuda as pessoas idosas, próximas da morte, a sentirem que a viveram de forma plena e completa (BROCK, 1998).

A mensuração contemporânea da qualidade de vida urbana deve incluir como elementos fundamentais: 1 . Dimensionamento da equidade no acesso social e espacial da população aos bens e serviços urbanos; 2. Avaliação da qualidade ambiental, partindo de aspectos socioambientais e aspectos ambientais "stricto senso"; 3 . Produção de elementos para discussão da sustentabilidade no desenvolvimento humano. 


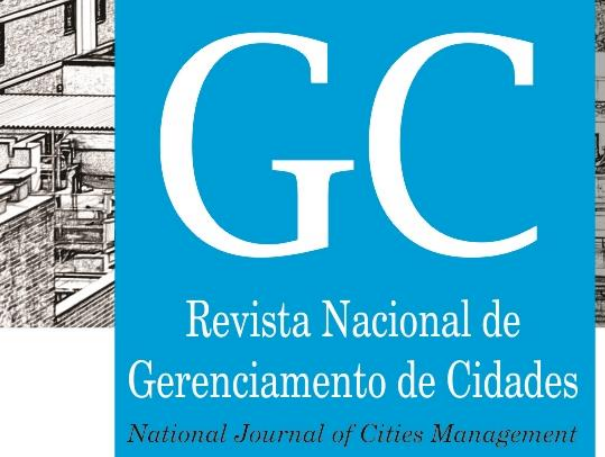

\section{EXPERIÊNCIAS INTERNACIONAIS}

\subsection{ISO 37120 - Desenvolvimento Sustentável Das Comunidades: Indicadores de Serviços e Qualidade de Vida da Cidade ${ }^{1}$ e NBR ISO 37120:2017 (versão brasileira)}

A ISO 37120 é a primeira norma internacional da International Organization for Standardization (ISO) em indicadores de cidade, definindo metodologias para orientar e medir o desempenho dos serviços e qualidade de vida urbana. Em 2012 a ISO criou um comitê técnico ${ }^{2}$ para definir requisitos, orientações, técnicas e ferramentas para a busca do desenvolvimento urbano sustentável, finalizando o trabalho em 2014, com a publicação da ISO 37120 (MATSUI, 2016; ISO, 2014).

A ISO 37120 tem como objetivo contribuir para o desenvolvimento sustentável das cidades e garantir que os cidadãos tenham acesso a serviços de qualidade. A norma analisa o desenvolvimento sustentável por meio de 17 áreas temáticas, com um total de 100 indicadores (Quadro 1). A certificação se dá com a exigência de 46 indicadores básicos ou essenciais (core indicators) e os demais indicadores (de apoio), classificados em 4 níveis: bronze, prata, ouro e platina. Foi criado o World Council on City Data (WCCD), primeiro órgão de certificação, oferecendo diversas formas de visualização dos indicadores, permitindo comparação direta entre cidades (MATSUI, 2016).

Quadro 1: Relação das áreas temáticas da ISO 37120 - Desenvolvimento sustentável das comunidades: indicadores de serviços e qualidade de vida da cidade

\begin{tabular}{|c|}
\hline ÁREAS TEMÁTICAS \\
\hline 1. Economia \\
2. Educação \\
3. Energia \\
4. Meio ambiente \\
5. Finanças \\
6. Resposta à incêndio e emergências \\
7. Governança \\
8. Saúde \\
9. Lazer/Recreação \\
10. Segurança \\
11. Habitação \\
12. Resíduos sólidos \\
13. Telecomunicação e inovação \\
14. Transporte \\
15. Planejamento urbano \\
16. Esgotamento sanitário \\
17. Água e saneamento
\end{tabular}

Fonte: ISO 37120, 2014 e ABNT, 2017.

\footnotetext{
${ }^{1}$ ISO 37120 - SUSTAINABLE DEVELOPMENT OF COMMUNITIES - INDICATORS FOR CITY SERVICES AND QUALITY OF LIFE

${ }^{2}$ ISO/TC 268 Sustainable development in communities
} 


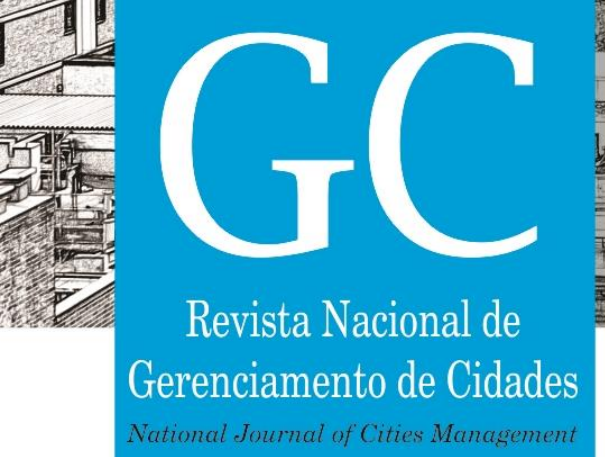

Avalia-se as áreas de qualidade de vida que são base para os indicadores objetivos de resultados, sendo que ambos tipos de indicadores tem o mesmo nível de importância (Quadro 5).

\section{Quadro 4: Dimensões da Rede Colombiana de Cidades “Como Vamos”}

\begin{tabular}{|c|}
\hline DIMENSÃo \\
\hline 1. Demografia \\
2. Pobreza e desigualdade \\
3. Saúde \\
4. Educação \\
5. Mercado de trabalho \\
6. Seguridade cidadã (Segurança) \\
7. Habitação e serviços públicos \\
8. Meio ambiente \\
9. Mobilidade \\
10. Espaço público \\
11. Cultura, recreação e esporte \\
12. Participação e cultura cidadã \\
13. Finanças e gestão pública \\
14. Ambiente econômico
\end{tabular}

Fonte: CORONA, 2014

Quadro 5: Componentes da Pesquisa de Percepção Cidadã

\begin{tabular}{|l|l|}
\hline TEMA & CONTEÚDO \\
\hline Clima de opinião & Como vão as coisas e nível de orgulho e satisfação com a cidade \\
\hline Situação econômico & Situação atual com relação ao ano anterior, principais problemas \\
\hline Educação & $\begin{array}{l}\text { Acesso da população em idade escolar, qualificação do serviço e razões } \\
\text { para a qualificação }\end{array}$ \\
\hline Saúde & $\begin{array}{l}\text { Acesso ao serviço, tipo de afiliação, qualificação do serviço e razões para } \\
\text { a qualificação }\end{array}$ \\
\hline Infraestrutura do bairro & Iluminação, vias de acesso, parques, áreas verdes, calçadas separadas \\
\hline Segurança cidadã & Nível de segurança, problemas, avanços e recomendações para melhorar \\
\hline Mobilidade rodoviária & $\begin{array}{l}\text { Tempo de deslocamento, qualificação das vias, meios de transporte, } \\
\text { trânsito }\end{array}$ \\
\hline Meio ambiente & Nível de ruído, poluição sonora, visual e de lixo \\
\hline Gestão pública & $\begin{array}{l}\text { Nível de confiança, qualificação da gestão e qualificação da atenção ao } \\
\text { usuário }\end{array}$ \\
\hline
\end{tabular}

Fonte: CORONA, 2014

\section{5 Índice de Qualidade de Vida Urbana Colombiano - ICVU ${ }^{9}$}

$\mathrm{Na}$ Colômbia tem sido desenvolvido diversos trabalhos orientados ao estudo da qualidade de vida urbana e seus fatores associados. Para essa avaliação, Eras et al (2017) aplicou um ICVU considerando as dimensões: social, econômica, Serviços e gestão e ambiental. Os indicadores

\footnotetext{
${ }^{9} \mathrm{ICVU}$ - Índice de calidad de vida urbana
} 
